\title{
Numerical Analysis of a Gravity Substructure for 5MW Offshore Wind Turbine
}

\author{
Min-Su Park, Youn-Ju Jeong, Young-Jun You, and Jeongsoo Kim
}

\begin{abstract}
The substructure for offshore wind turbine is strongly influenced by wave forces as the size of substructure increases. Since a large offshore wind turbine has a heavy dead load, the reaction forces on the substructure become severe. Therefore, the very firm foundation should be required and the soil-structure interaction should be considered. When the structure is large compared to the wave length, the diffraction of waves should be considered. In the present study ANSYS AQWA is used to evaluate the wave forces acting on the gravity substructure. The wave forces and panel pressure on the gravity substructure are presented for various wave conditions. Moreover, the foundation stiffness of gravity substructure is determined based on the DNV-OS-J101 formulae from elastic theory. Using the wave forces and foundation stiffness matrix obtained from this study, the structural analysis of the gravity substructure is carried out through ANSYS mechanical. The structural behaviors of the strength and deformation are evaluated to investigate an ultimate structural safety of gravity substructure for various wave conditions. Also, the modal analysis is carried out to investigate the resonance between the wind turbine and the gravity substructure. It is found that the suggested gravity substructure can be an effective substructure for reducing hydrodynamic effects and construction costs in jeju island sea of Korea.
\end{abstract}

Key words-Offshore wind energy, Gravity substructure, Modal analysis, Structural analysis, soil-structure interaction.

\section{INTRODUCTION}

Nowadays, the main source of energy in the world is fossil fuel. But the amount of fossil fuel is limited and the use of it causes environmental pollution and global warming. The offshore wind energy has gained attention from many countries to find alternative and reliable energy sources since the potential of offshore wind energy has been recognized for long and mostly associated with a nondestructive renewable energy. Particularly in Europe, wind farms are planned to be established at a greater water depth with larger turbines. Various studies have been conducted on wind energy [1]-[3]. In order to construct the offshore wind farms, the substructures supporting offshore wind turbines have to resist loads from wind and wave. However, the substructure is strongly influenced by the effect of wave forces as the size of substructure increases and the safety of substructure is decreased. Therefore, it is very important to accurately calculate the wave forces acting on substructures. When the

Manuscript received November 21, 2016; revised May 21, 2017.

The authors are with the Structural Engineering Research Institute, Korea Institute of Civil Engineering and Building Technology, Goyang-Si, South Korea (e-mail: mspark@kict.re.kr, yjjeong@kict.re.kr, yjyou@kict.re.kr, jeongsookim@kict.re.kr). substructure is large, compared to the wave length, Morison's equation is no longer applicable. In Particular, if the substructure spans a significant portion of a wave length, the incident waves upon arriving at the substructure undergo significant scattering or diffraction. In this case the diffraction of waves from the surface of the substructure should be considered in the wave force calculations [4].

In addition, since a large offshore wind turbine has heavy dead loads, the reaction forces on the foundations become severe, thus very firm foundations should be required. Therefore, the soil-structure interaction has to be fully considered. There are two main methods for the analysis of structure-foundation interaction, direct and substructure method, as outlined by Wolf [5], [6].

In the present study ANSYS AQWA is used to evaluate the wave forces acting on the gravity substructure for $5 \mathrm{MW}$ offshore wind turbine since Morison's equation cannot accurately calculate the wave forces in case of the large substructure compared to a wave length. The wave forces and panel pressure on the substructure are presented for various wave conditions. Since a large offshore wind turbine has a heavy dead load, the reaction forces on the substructure become severe, thus very firm foundations should be required. Therefore, soil-structure interaction model should be cleverly chosen according to analysis type with performing a sensitivity analysis. Some guidelines such as DNV, API and GL are recommended that the full nonlinear model must be used for extreme load cases and foundation design. In the present study the DNV-OS-J101 formulae from elastic theory is used to calculate the foundation stiffness matrix on the soil-structure interaction conditions. Using the wave forces and the foundation stiffness matrix obtained from this study, the structural analysis of the gravity substructure is carried out through ANSYS mechanical. The structural behaviors of the strength and deformation are evaluated to investigate an ultimate structural safety of gravity substructure for various wave conditions. The first few natural frequencies of substructure are heavily influenced by the wind turbine. Therefore, the first natural frequency of substructure is to be within the soft-stiff range in between the $1 \mathrm{P}$ and $3 \mathrm{P}$ frequency ranges. The rotor frequency (1P) range lies between $0.115 \mathrm{~Hz}$ and $0.202 \mathrm{~Hz}$, and the blade passing frequency $(3 \mathrm{P})$ range lies between $0.35 \mathrm{~Hz}$ and $0.61 \mathrm{~Hz}$. A safety margin of $10 \%$ on the maximum and minimum rotor speed is adopted, which means that the allowable frequency is between $0.222 \mathrm{~Hz}$ and $0.31 \mathrm{~Hz}$ [7]. Therefore, the modal analysis is carried out to investigate the resonance between the wind turbine and the gravity substructure. It is found that the suggested gravity substructure can be an effective substructure for 5MW offshore wind turbines. 


\section{NUMERICAL MODEL AND ENVIRONMENTAL CONDITION}

\section{A. Wind Turbine and Substructure Model}

The NREL 5.0MW wind turbine model is selected for the structural safety analysis of gravity substructure. The details of NREL 5.0MW wind turbine are provided in Table I. The total weights of turbine and the tower model are about 350 and 348ton, respectively. The hub height is $88.35 \mathrm{~m}$ from MSL (Mean Sea Level) and the tower length is $68.0 \mathrm{~m}$ [8]. The gravity substructure for $5 \mathrm{MW}$ offshore wind turbine composes of a prestressed concrete (compressive strength: $45 \mathrm{MPa}$ ) with $0.5 \mathrm{~m}$ thickness and the height of gravity substructure is $47.0 \mathrm{~m}$ from seabed as shown in Fig. 1 .

TABLE I: DETAILS OF NREL 5MW WIND TURBINE MODEL

\begin{tabular}{ccc}
\hline \hline Turbine Parameter & Unit & Value \\
\hline Rating & MW & 5 \\
Configuration & - & 3 blades \\
Rotor, Hub diameter & $\mathrm{m}$ & 126,3 \\
Cut-in, Rated wind speed & $\mathrm{m} / \mathrm{s}$ & $3,11.4$ \\
Cut-in, Rated rotor speed & $\mathrm{rpm}$ & $6.9,12.1$ \\
Cut-out wind speed & $\mathrm{m} / \mathrm{s}$ & 25 \\
Rated tip speed & $\mathrm{m} / \mathrm{s}$ & 80 \\
Rotor mass & $\mathrm{kg}$ & 110,000 \\
Nacelle mass & $\mathrm{kg}$ & 240,000 \\
Tower mass & $\mathrm{kg}$ & 347,460 \\
Coordinate location of overall CM & $\mathrm{m}$ & $(-0.2,0.0,64.0)$ \\
\hline \hline
\end{tabular}

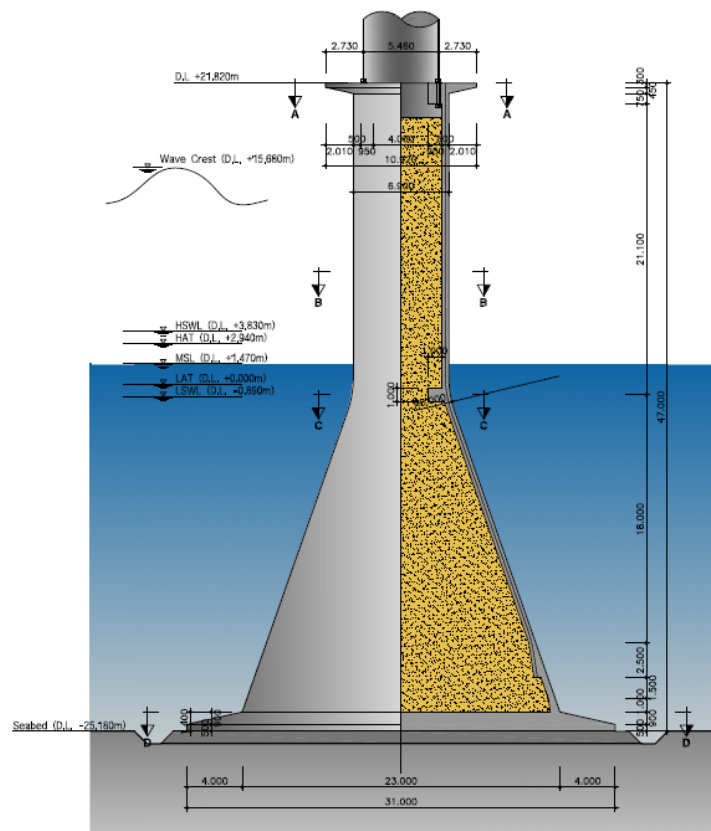

Fig. 1. Geometrical definition of the gravity substructure.

\section{B. Design Load Cases and Environmental Condition}

Design code IEC 61400-3 is adopted and structure analysis is carried out according to the ultimate design loads condition 6.1(a) and 6.2(a) presented in Table II.

TABLE II: DESIGN LOAD CASES FOR UlTiMATE Limit STATE

\begin{tabular}{|c|c|c|c|}
\hline DLC & Condition & Wave & Wind \\
\hline IEC 61400-3-(6.1a) & $\begin{array}{c}\text { Parked standing still or } \\
\text { idling }\end{array}$ & Extreme & Extreme \\
\hline IEC 61400-3-(6.2a) & Grid loss & Extreme & Extreme \\
\hline
\end{tabular}

Environmental loads of wind and wave for the jeju island sea of Korea are presented in Table III. Extreme wind and wave loads subjected to the gravity substructure are calculated based on the wind speed and the wave period of return period 50 years.

TABLE III: ENVIRONMENTAL CONDITION

\begin{tabular}{ccc}
\hline \hline Condition & Wind & Wave \\
\hline Extreme & $41.6 \mathrm{~m} / \mathrm{s}$ & $\mathrm{H}_{\max }=16.02 \mathrm{~m}, \mathrm{~T}_{\mathrm{w}}=14.25 \mathrm{sec}$ \\
\hline \hline
\end{tabular}

\section{Foundation Stiffness Matrix}

When the soil conditions are fairly homogeneous and an equivalent shear modulus $\mathrm{G}$ can be determined, representative for the participating soil volume as well as for the prevailing strain level in the soil, then the foundation stiffness may be determined based on formulae from elastic theory as shown in Table 4. DNV recommend that foundation springs based on these formulae will be representative for the dynamic foundation stiffness that are needed in structural analyses for wind and wave loading on the wind turbine and its support structure. In structural analyses for earthquake loads, however, it may be necessary to apply frequency-dependent reductions of the stiffnesses from Table 4 to get appropriate dynamic stiffness values for the analyses [9]. Table 4 offers simple and quite accurate formulate for the determinatin of the static stiffnesses. These results have been drived by several studies [10]-[14].

Table V and VI present the design parameters of jeju island and the foundation stiffness obtained from the present study, respectively.

TABLE IV: FOUNDATION FORMULAE

\begin{tabular}{ccc}
\hline \hline Mode of motion & Foundation stiffness \\
\hline Vertical & $K_{V}=\frac{4 G R}{1-v}\left(1+1.28 \frac{R}{H}\right)$ \\
Horizontal & $K_{H}=\frac{8 G R}{2-v}\left(1+\frac{R}{2 H}\right)$ \\
Rocking & $K_{R}=\frac{8 G R^{3}}{3(1-v)}\left(1+\frac{R}{6 H}\right)$ \\
Torsion & $K_{T}=\frac{16 G R^{3}}{3}$ \\
\hline \hline & Figure \\
\hline
\end{tabular}

TABLE V: DESIGN PARAMETERS OF JEJU ISLAND

\begin{tabular}{cc}
\hline \hline Parameter & Value \\
\hline Foundation radius (R) & $15.5 \mathrm{~m}$ \\
Stratum depth $(\mathrm{H})$ & $1.2 \mathrm{~m}$ \\
Shear Modulus $(\mathrm{G})$ & $96.2 \mathrm{MPa}$ \\
Poisson's ratio & 0.3 \\
\hline \hline TABLE VI: FOUNDATION STIFFNESS OF JEJU ISLAND \\
\hline \hline Component & Value \\
\hline$K_{V}$ & $149.394 \times 10^{9} \mathrm{~N} / \mathrm{m}$ \\
$K_{H}$ & $52.335 \times 10^{9} \mathrm{~N} / \mathrm{m}$ \\
$K_{R}$ & $4.302 \times 10^{12} \mathrm{Nm} / \mathrm{rad}$ \\
$K_{T}$ & $1.910 \times 10^{12} \mathrm{Nm} / \mathrm{rad}$ \\
\hline \hline
\end{tabular}




\section{NUMERICAL RESULTS AND DISCUSSION}

\section{A. Wave Force Evaluation}

In the present study ANSYS AQWA is used to evaluate the wave forces acting on the gravity substructure for $5 \mathrm{MW}$ offshore wind turbine. The ANSYS AQWA provides an engineering toolset for the investigation of the effects of wave, wind and current on floating and fixed offshore structures. Three-dimensional linear radiation and diffraction analysis may be undertaken with multiple bodies, taking full account of hydrodynamic interaction effects that occur between bodies [15]. Fig. 2 shows the comparison of wave forces on the gravity substructure for various water depths. The water depth of highest still water level (HSWL), mean sea level (MSL) and lowest still water level (LSWL) is $29.01 \mathrm{~m}$, $26.65 \mathrm{~m}$ and $24.29 \mathrm{~m}$ from the seabed, respectively. In the comparison, the calculated total wave forces are divided by incident wave amplitude (H/2). The wave forces on the gravity substructure with the water depth LSWL are largest compared to the other cases. Since the wave force is closely related to the wetted surface of substructure and the water particle velocity near free surface is largest, the wave forces gradually increase as the water depth becomes small. The peak wave force with water depth MSL and HSWL decreases about $10 \%$ and $18 \%$ compared to the peak value of water depth LSWL.

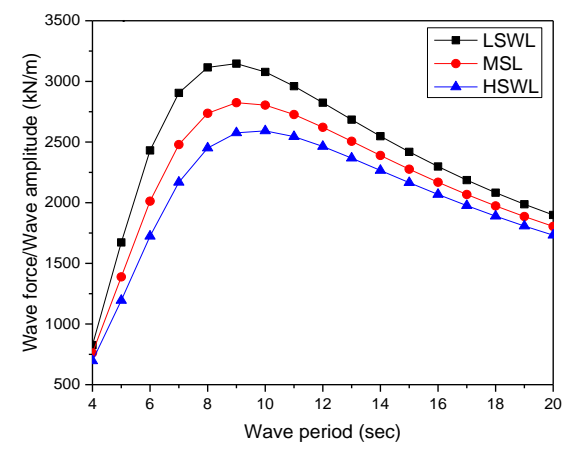

Fig. 2. Comparison of wave forces for various water depths.

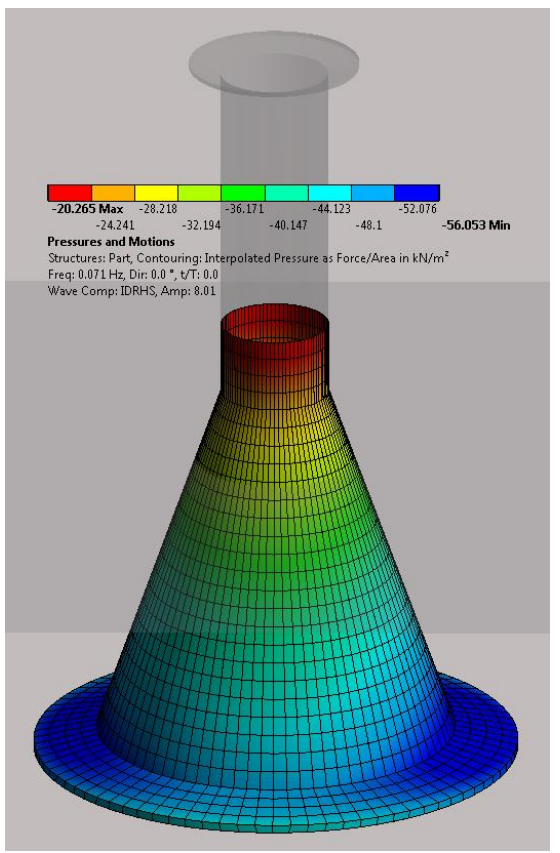

(a) Panel Pressure for HSWL

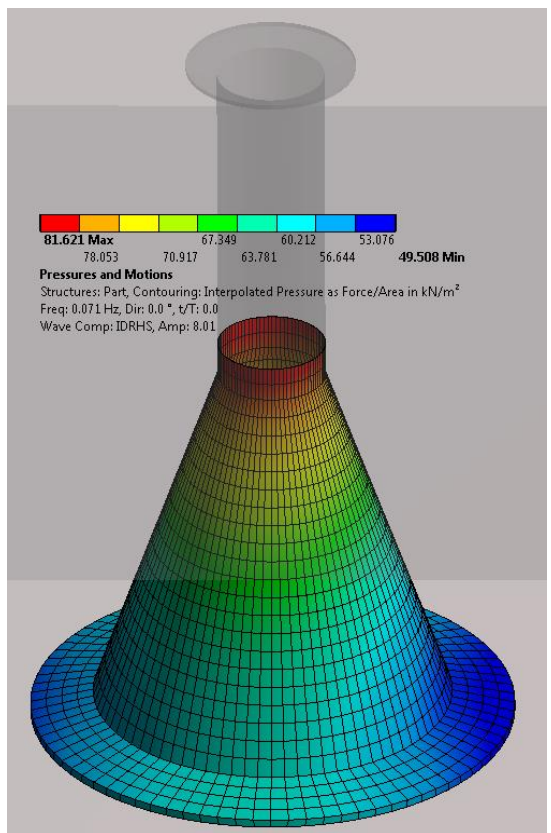

(b) Panel Pressure for MSL

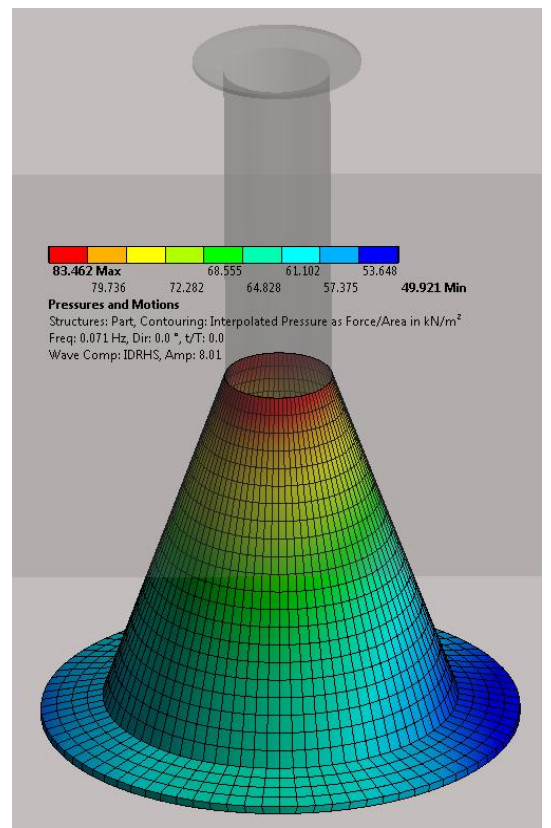

(c) Panel Pressure for LSWL

Fig. 3. Panel pressure on gravity substructure: (a) HSWL, (b) MSL, (c) LSWL.

Fig. 3 examines the panel pressure on gravity substructure. Since the design wave period of jeju island sea in Korea is $14.25 \mathrm{sec}$ and design wave height is $16.02 \mathrm{~m}$, the comparison is made at the same wave condition. The panel pressure near the free surface is largest.

\section{B. Natural Frequency and Resonance}

The modal analysis is carried out to evaluate the resonance between the wind turbine and the gravity substructure. The natural frequencies, the mode shapes, and allowable natural frequency of gravity substructure present in Table VII, Fig 4 , and Fig 5, respectively. It is found that the natural frequency of gravity substructure system is located between the rotor frequency range (1P) and the blade passing frequency range (3P). Therefore, the resonance between the wind turbine and the gravity substructure is not occurred. 


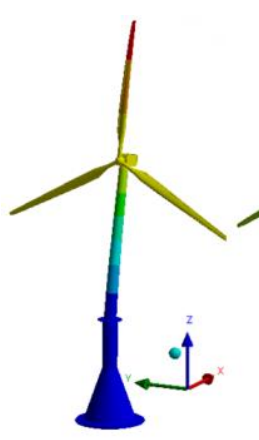

$<1^{\text {st }}$ mode $>$

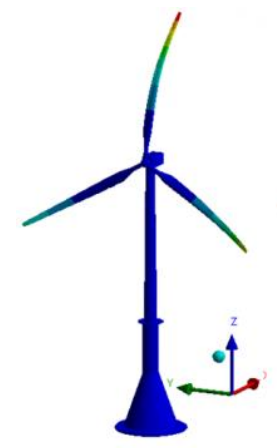

$<4^{\text {th }}$ mode $>$

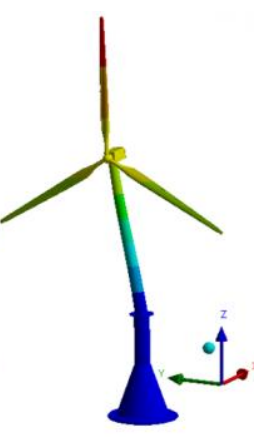

$<2^{\text {nd }}$ mode $>$

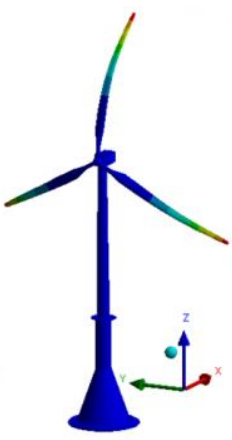

$<\mathbf{5}^{\text {th }}$ mode $>$

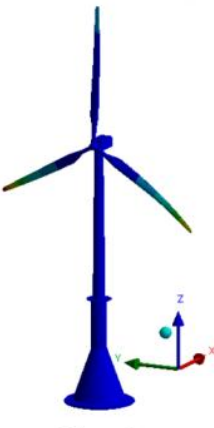

$<3^{\text {rd }}$ mode $>$

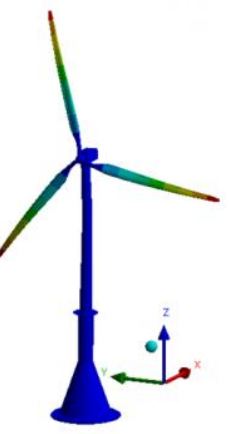

$<6^{\text {th }}$ mode $>$

Fig. 4. Mode shapes of gravity substructure.

TABLE VII: NATURAL FREQUENCIES OF GRAVITY SUBSTRUCTURE

\begin{tabular}{cccc}
\hline \hline Mode & Frequency $(\mathrm{Hz})$ & Mode & Frequency $(\mathrm{Hz})$ \\
\hline 1 & 0.23387 & 6 & 1.1807 \\
2 & 0.28926 & 7 & 1.2957 \\
3 & 0.78312 & 8 & 1.3288 \\
4 & 0.78757 & 9 & 2.3181 \\
5 & 0.8522 & 10 & 2.4208 \\
\hline \hline
\end{tabular}

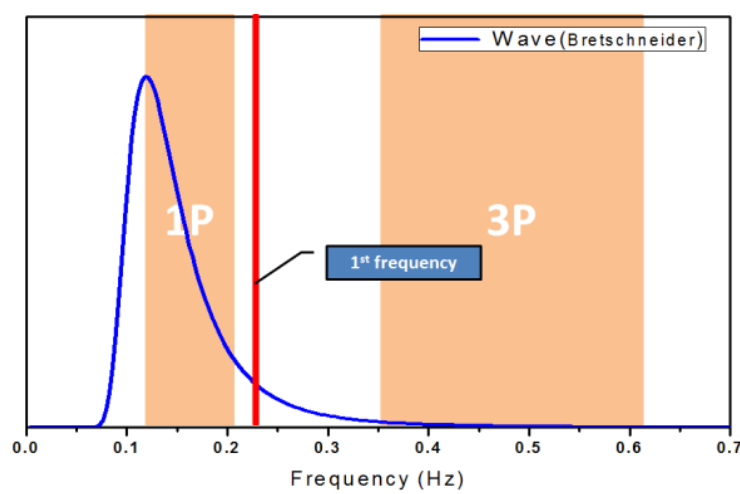

Fig. 5. Allowable natural frequency range for the gravity substructure.

\section{Structural Results}

Table VIII shows the loads at transition pieces (TP) due to extreme wind. In the present study, the extreme values at TP for DLC 6.2a are used since the case of DLC 6.2a is largest.

\begin{tabular}{ccccccc}
\multicolumn{7}{c}{ TABLE VIII: EXTREME VALUES AT TP DuE TO WIND } \\
\hline \hline DLC & $\begin{array}{c}\text { Fx } \\
(\mathrm{kN})\end{array}$ & $\begin{array}{c}\text { Fy } \\
(\mathrm{kN})\end{array}$ & $\begin{array}{c}\mathrm{Fz} \\
(\mathrm{kN})\end{array}$ & $\begin{array}{c}\mathrm{Mx} \\
(\mathrm{kNm})\end{array}$ & $\begin{array}{c}\mathrm{My} \\
(\mathrm{kNm})\end{array}$ & $\begin{array}{c}\mathrm{Mz} \\
(\mathrm{kNm})\end{array}$ \\
\hline $6.1 \mathrm{a}$ & 324 & 225 & $-6,049$ & 21,481 & 3,765 & 236 \\
$6.2 \mathrm{a}$ & 1,364 & 571 & $-6,322$ & 39,827 & 82,343 & 2,610 \\
\hline \hline
\end{tabular}

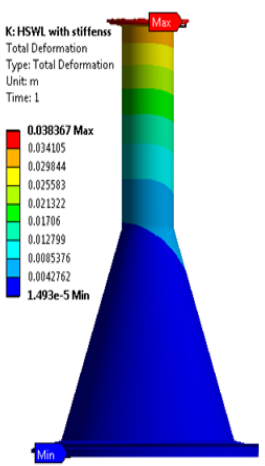

(a) HSWL

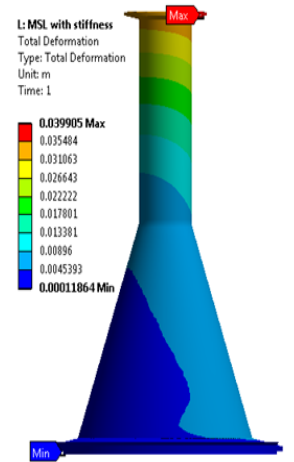

(b) MSL

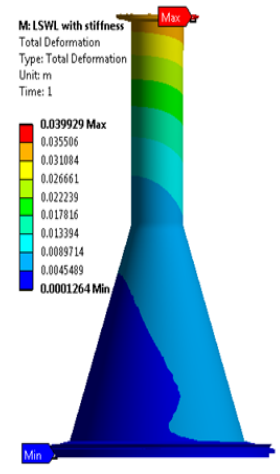

(c) LSWL
Fig. 6. Structural displacement due to water depth conditions.

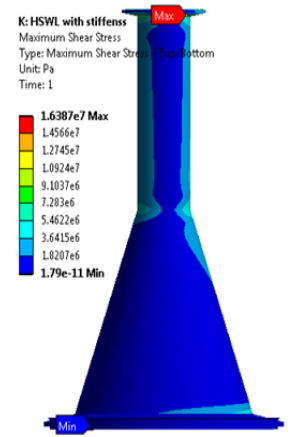

(a) HSWL

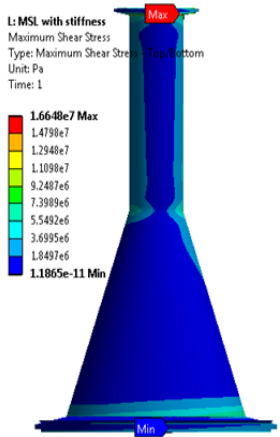

(b) MSL

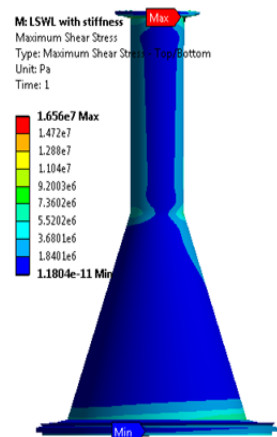

(c) LSWL
Fig. 7. Structural maximum shear stress due to water depth conditions.

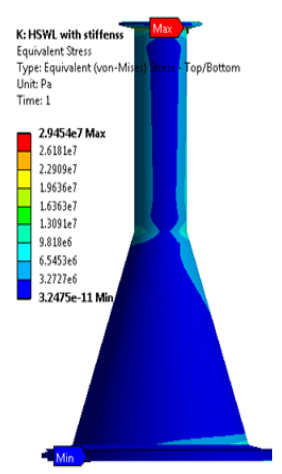

(a) HSWL

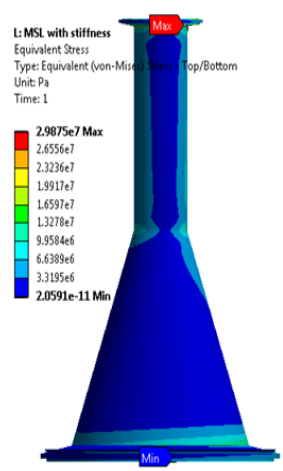

(b) MSL

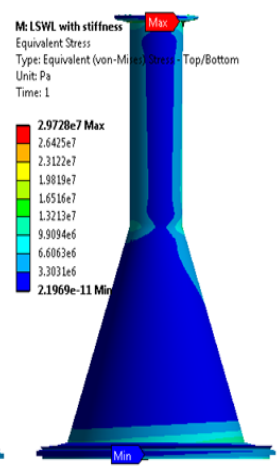

(c) LSWL
Fig. 8. Structural von-mises stress due to water depth conditions.

TABLE IX: STRUCTURAL RESULTS

\begin{tabular}{ccccc}
\hline \hline & & HSWL & MSL & LSWL \\
\hline Displacement & Max & 0.03836 & 0.03990 & 0.03992 \\
$(\mathrm{~m})$ & Min & 0.00001 & 0.00011 & 0.00012 \\
\hline Shear stress & Max & 16.387 & 16.648 & 16.560 \\
$(\mathrm{MPa})$ & Min & 0.0000 & 0.0000 & 0.0000 \\
\hline Von-Mises stress & Max & 29.454 & 29.875 & 29.728 \\
$(\mathrm{MPa})$ & Min & 0.0000 & 0.0000 & 0.0000 \\
\hline Normal stress & Max & 24.710 & 25.152 & 25.439 \\
(x axis, MPa) & Min & -31.319 & -31.851 & -31.726 \\
\hline Normal stress & Max & 20.754 & 19.859 & 21.465 \\
(y axis, MPa) & Min & -26.847 & -26.904 & -26.733 \\
\hline Normal stress & Max & 12.109 & 12.029 & 12.114 \\
(z axis, MPa) & Min & -17.932 & -17.895 & -17.930 \\
\hline \hline
\end{tabular}

ANSYS AQWA can also generate pressure and inertial loading for use in a structural analysis as part of the offshore structure design process. The results from a diffraction analysis can be mapped onto an ANSYS Mechanical finite 
element model for further structural assessment and detailed design [15]. Using the wave forces, the wind loads at TP, and the foundation stiffness matrix, the structural analysis of gravity substructure is carried out through ANSYS mechanical. The structural displacement, the shear stress and the Von-Mises stress are plotted at the Fig. 6, Fig. 7, and Fig. 8 for various water depths, respectively. Since the wave forces acting on the gravity substructure increase as the water depth becomes small, the displacement has the largest value at LSWL. However, the shear stress and the Von-Mises stress have the largest value at MSL. The structural results are summarized at Table IX. It is found that the ultimate strength of gravity substructure system satisfies ULS design condition for various wave conditions.

\section{CONCLUSION}

Since Morison's equation cannot accurately calculate the wave forces in case of the large substructure compared to a wave length ANSYS AQWA is used to evaluate the wave forces acting on the gravity substructure for $5 \mathrm{MW}$ offshore wind turbine. It is found that the total wave forces on gravity substructure gradually decrease as the water depth increases because the wave force is closely related to the wetted surface of substructure and the water particle velocity near free surface is largest. Using the wave forces and foundation stiffness, the structural analysis of the gravity substructure for $5 \mathrm{MW}$ offshore wind turbine is carried out through ANSYS mechanical for various water depths. From the structural analysis of gravity substructure, it is found that the gravity substructure system satisfy structural safety in respect of ULS (ultimate limit state). Also, the resonance between the wind turbine and the gravity substructure is not occurred. Consequently, the suggested gravity substructure can be an effective substructure for reducing hydrodynamic effects and construction costs in jeju island sea of Korea.

\section{ACKNOWLEDGMENT}

This research was supported by Korea Institute of Marine Science and Technology Promotion (KIMST) through the research project "Safety evaluation of concrete substructure systems for offshore wind power (20120093)", and by Korea Institute of Energy Technology Evaluation and Planning (KETEP) through the research project "Development of $3 \mathrm{~kW}$ cylindrical wave energy system with horizontal rotation for increasing gross generation (20153030071630)".

\section{REFERENCES}

[1] W. Jan, R. Marte., S. Christian, and G. H. Edgar, "Life cycle assessment of a floating offshore wind turbine," Renew Energy, vol. 34, no. 3 , pp. $742-747,2009$

[2] J. M. Jonkman, 2009, "Dynamics of offshore floating wind turbines-model development and verification," Wind Energy, vol. 12, no. 5 , pp. $459-492$.

[3] E. Lozano-Minguez, A. J. Kolios, and F. P. Brennan, "Multi-criteria assessment of offshore wind turbine support structures," Renew Energy, vol. 36, pp. 2381-2387, 2011.

[4] M. S. Park, Y. J. Jeong, and Y. J. You, "Numerical Analysis of a Gravity substructure for $5 \mathrm{MW}$ offshore wind turbines due to soil conditions," Journal of Energy and Power Engineering, vol. 10, pp. $150-158,2016$
[5] J. P. Wolf, "Dynamic soil structure interaction," New Jersey: Prentice Hall, Inc., Englewood Cliffs, 1985.

[6] J. P. Wolf, "Soil structure interaction analysis in time domain," New Jersey: Prentice Hall, Inc., Englewood Cliffs, 1988.

[7] T. Fischer, W. De Vries, and B. Schmidt, "Upwind Design Basis (WP4: Offshore Foundations and Support Structures)," Upwind, 2010

[8] J. Jonkman, S. Butterfield, W. Musial, and G. Scott, "Definition of a 5MW reference wind turbine for offshore system development," National Renewable Energy Laboratory, 2009.

[9] DNV, 2013, "DNV-OS-J101: Design of offshore wind turbine structures," Det Norske Veritas AS.

[10] E. Kausel, "Forced vibrations of circular foundations on layered media," Research Report R74-11, MIT, 1974.

[11] E. Kausel and J. M. Roesset, "Dynamic stiffness of circular foundations," Journal of the Engineering Mechanics Division, ASCE, vol. 101, no. 6, pp. 771-785, 1975 .

[12] E. Kausel and R. Ushijima, "Vertical and torsional stiffness of cylindrical footings," Research Report R 76-6, MIT, 1979.

[13] J. M. Roesset, "Stiffness and damping coefficients of foundation," Dynamic response of pile foudations, Prodeedings of ASCE, 1980.

[14] S. S. Chen and J. Y. Shi, "Simple models of foundation-soil interaction," IACSIT International Journal of Engineering and Technology, vol. 5, no. 5, pp. 573-577, 2013.

[15] ANSYS, “Aqwa user's manual,” ANSYS Inc., 2013.

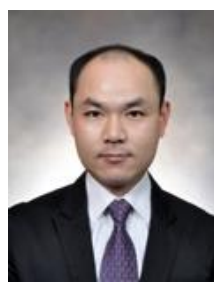

Min-Su Park earned the Ph.D degree in system information engineering from Kagoshima University, Kagoshima, Japan. He has been working for Korea Institute of Civil Engineering and Building Technology (KICT) in Gyeonggi-Do, Korea since 2012 and his current position is senior researcher. He participated in some projects for the offshore structure and offshore renewable energy. He now studies on wave energy devices and substructure for offshore wind turbine. Dr. Park is a member of KSCE (Korean Society of Civil Engineers), KSOE (Korean Society of Ocean Engineers), SNAK (Society of Naval Architects of Korea) and KCI (Korea Concrete Institute).

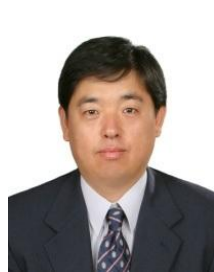

Young Jeong earned the Ph.D degree in civil engineering from Yonsei University, Seoul, Korea. He has been working for Korea Institute of Civil Engineering and Building Technology (KICT) in Gyeonggi-Do, Korea since 1994 and his current position is RESEARCH FELLOW. He participated in some projects for the offshore and marine structures. He now studies on offshore support structure. Dr. Jeong is a member of KSCE (Korean Society of Civil Engineers) and COSEIK (Computational Structural Engineering Institute of Korea).

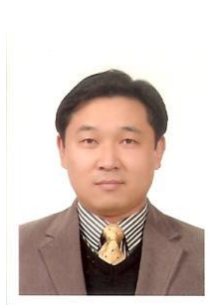

Young Jun You earned the Ph.D degree in civil engineering from Yonsei University, Seoul, Korea. He has been working for Korea Institute of Civil Engineering and Building Technology (KICT) in Gyeonggi-Do, Korea since 1998 and his current position is senior researcher. He participated in some projects for developing GFRP (Glass Fiber Reinforced Polymer) reinforcement for concrete structures and strengthening and rehabilitation of structures. He now studies on offshore support structures.

Dr. You is a member of KSCE (Korean Society of Civil Engineers) and $\mathrm{KCI}$ (Korea Concrete Institute), especially was a former representative of $\mathrm{KCI}$

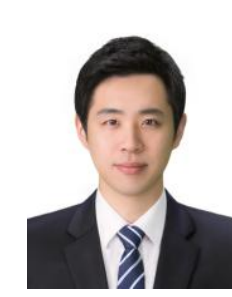

Jeongsoo Kim earned the $\mathrm{Ph}$. D. degree in civil engineering from Yonsei University, Seoul, Korea. $\mathrm{He}$ has been working for Korea Institute of Civil Engineering and Building Technology (KICT) as a post-doctor researcher. He participated in some projects for tunnel supports and pipeline in the frozen ground. He currently studies on substructure of offshore wind turbine and wave energy devices. Dr. Kim is a member of Korean Society of Civil Engineers (KSCE) and Korean Geotechnical Society (KGS). 